\title{
Erratic or Intermittent Display
}

National Cancer Institute

\section{Source}

National Cancer Institute. Erratic or Intermittent Display. NCI Thesaurus. Code C63207.

A device that does not consistently display the same message, result, reading, or image.

e.g. the display might flicker, switch between readings or messages, or go completely blank for brief periods of time. 